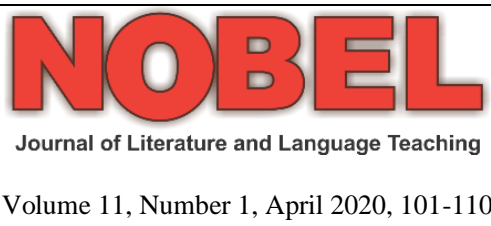

available at http://jurnalfahum.uinsby.ac.id/index.php/nobel/article/view/nomorurut

DOI: 10.15642/NOBEL.2020.11.1.101-110

\title{
HESITATION PHENOMENA IN CONVERSATIONAL INTERACTION AMONG SPEAKING EFL LEARNERS
}

\author{
Rohmatul Fitriyah Dewi ${ }^{凶}$ \\ Universitas Negeri Surabaya, Jalan Rektorat Unesa, Lidah Wetan, Surabaya, Indonesia
}

\begin{tabular}{l}
\hline Article Info \\
\hline Article History: \\
Received February 2018 \\
Accepted October 2018 \\
Published April 2020 \\
\hline Keywords: \\
hesitation phenomena, \\
conversational interaction, \\
EFL learners \\
\hline
\end{tabular}

\begin{abstract}
Hesitation is the phenomenon when people have speech disfluency in structuring sentences. English Conversation Club is one of the domains where hesitation phenomena occur among EFL learners that practicing their conversation. This study examines the hesitation phenomena and why the members are being hesitated during the interaction. Rose's theory of taxonomy of hesitation phenomena (2012) is adopted. The approach used is the qualitative approach. Besides, the writer is also the participant observation to collect the data by recording and taking notes. This study resulted that most of the hesitation phenomena are found in the conversation conducted by the learners. The reason for being hesitant is unable to express the language and poor communication skills. Those occur spontaneously and naturally due to the reason that the processing of language in the brain is not as easy as it is produced directly.
\end{abstract}




\section{INTRODUCTION}

Language seems to play a central role in guiding and perhaps even determining our thoughts (Harley, 2010). In terms of communication, human thoughts are important as part of thinking in the usage of language. Language is not as simple as what people think about; however, Cowles (2011) points out that some minor delays during language processing are thought to have profound consequences. These consequences can be realized through the human speech production that is uttered by people who want to express, discuss, and share about particular things. Levelt (1989), cited in Carroll (2007), distinguishes four major stages of speech production, they are conceptualizing a thought to be expressed, formulating a linguistic plan, articulating the plan, and monitoring one's speech. Employing these stages, the human language is processed in the brain to produce and acquire a proper language.

One of the human speech productions is the conversation, as it is a special form to have social interaction. In some cases, the different structures of a certain situation will have different rules. Regardless of the social use of language, rules for taking turns, and for maintaining and changing topics are involved (Carroll, 2007). Human speech isn't absent from being flawed in the real conversation, yet the disfluency of, for instance, structuring the sentence, repeating the idea as the result of hesitation phenomena. It is about an integral part of speech, particularly unscripted and spontaneous speech that is marked by a silent pause, filled pause, false start, repeat/restart lengthening, and parenthetical remark (Rose, 2012).

The tendency of being hesitated is commonly occurred in daily speaking, especially in spontaneous speech, when people have to deal with the interaction in the English language. Hesitation may occur in the process of producing the sounds resulting in the disfluency of speech. Carroll (2007) defines that hesitations are a silent moment that emerges between the units of language in uttering sentences. Some previous studies show that hesitation phenomena give the influence to speech production and performance of LI and L2 learners (Rose, 2013; Reitbrecht \& Hirschfeld, 2015; Kosmala \& Morgenstern, 2017). Based on this, the present study attempts to explore the hesitation phenomena that naturally occur in EFL learners. ECC, which stands for English Conversation Club, is a place where EFL learners practice English, especially in the form of speaking. ECC is developed since the needs of society to learn English is rapidly increasing. It also provides a valuable lesson for them who wants to join as the members, either young or adult learners. The conversation becomes the main spoken discourse to conform to its practices.

In this community, the interactions through conversation may exchange to share ideas, experiences, or feelings among members from different social backgrounds. It is not 
surprising how the way EFL learners practice their English will emerge the disfluency of some features in producing spontaneous speech, that is, hesitation phenomenon. This study is interesting to be conducted to examine the hesitation phenomena found in the interaction among EFL learners in English conversation as well as the reason for being hesitant.

\section{REVIEW OF LITERATURE}

\section{Hesitation}

Hesitation is how people utilized silence for taking a breath during speaking, preparing the continuity of speaking, signaling the end of speaking, and taking a turn of speaking (Rose, 2012). It can be stated that hesitation is the period of silence in the middle of speaking or having a conversation. In language production, a term of silence refers to pause, the moment when people stop talking. How long a silence has to be before we can safely say in the normal articulation of speech, it is a pause (Warren, 2013). Pause is one of the types of hesitation which is fundamentally integrated into other terms of hesitation phenomena. These are an integral part of speech, particularly unscripted and spontaneous speech (Rose, 2012). In fact, all factors underlying hesitation phenomena can make delays to transfer information. The process of being hesitated is not only covering a single phenomenon of hesitation in producing the language but also some other phenomena may encourage its emergence. A categorization of hesitation phenomena is briefly discussed by Rose (2012) that is categorized into six types.

The first type is a silent pause. Silent pause or unfilled pause is the interval/duration of silence within speech. It is common for people who carry out a silent pause either in the middle or at the end of their conversation. Silent pause is also considered as a long pause, not as a juncture pause, that is, longer than 0.3-1.0 sec (Rose, 2012). The second type is filled pause. It occurs when speakers utter a syllable that consists of a centralized vowel as a nucleus and an optional nasal coda (uh/um, in English). It is in accordance with Harley (2001) that filled pause is a gap of words filled with a sound such as $u h$ or $u m$. The third type is lengthening. It deals with the prolongation of one or more segments of words. It often occurs on vowels but may also occur on consonants and even geminated consonants (by delaying the release) (Rose, 2012).

The fourth type is repeats/restarts. It refers to the repetition of a sequence of one or more words immediately. It usually occurs at the beginning of the utterance which is regarded as localized to articulatory problems rather than broader language production processes (Rose, 2012). The fifth type is false starts that occurs when a speaker begins an utterance and 
abandons it completely without finishing it. The last type is a self-correction which a speaker utters a sequence of one or more words that are to be understood as a replacement (i.e., correction) of the immediately preceding comparable sequence. That is, the communication of the speakers during the conversation in the case of delivering the message will be disturbed by the occurrence of hesitation phenomenon.

\section{Conversational Interaction}

Conversation is primarily oral discourse. It is planned and produced spontaneously which accounts for many of the ways it differs linguistically from written language or spoken language (Thornbury \& Slade, 2006). It is also the process of interchanging ideas, opinions or feelings. In both formal and informal settings, certain conventions of conversation are assigned as a rule for holding talks. Carroll (2007) called the conventions as the structures of conversation. They are: (1) opening conversation - address another person, request information, offer information, or use fixed expressions or topic, (2) closing conversation summary, justifying ending contact at this time, expressing pleasure about each other, making reference to the ongoing relationship and planning for future contact, (3) taking turns - the condition which speakers take a turn or a floor in talking, (4) negotiating topics of conversation - the condition which speakers are discussed a topic to be chosen, and (5) identifying participants and non participants.

To begin with, a conversation may not occur solely without any partners who provide reciprocity. Participants obviously have a great deal to make conversation run smoothly. They way of shared knowledge may influence the process of conversation (Carroll, 2007). To satisfy the conducted conversation, participants such as friends and acquaintances, are required enough to decide on a topic that is going to be examined. Moreover, the idea in which conversation takes place is the matter to do in a context. More generally, it appears that conversational setting may draw on principles of conversational behavior used in everyday speech (Carroll, 2007). For instance, taking turn and negotiation topic. These behaviors can emerge in the institutional speech in classroom discourse, the area where linguistic devices are processed and enacted within the classroom. Rymes (2009) affirms that classroom discourse analysis can be paraphrased as language-in-use in the classroom context to grasp how context and interaction are influencing each other.

\section{RESEARCH METHOD}

This research was conducted in ECC, one of English conversation community, in Surabaya. It consists of many EFL learners who attempt to practice speaking English based 
on different social and educational background. This research examines the hesitation phenomena found in the interaction among its learners when they utilize English as the language of their speech production. This study applied the qualitative approach. Creswell (2007) defines qualitative research as a form of inquiry which the research's interpretation outcome is about what they see, feel, hear and understand. Belonging to the member of this community, the writer conducted participant observation as it is focusing on the language used. It is important to note that as participant-observation, the researcher should interact with other participants, get to participate and perform in their activities (Gold, 1969; Spradley, 1980: 58-62; Williamson et al. 1982, cited in Duranti, 1997). In collecting the data, the writer outlines several steps. These are: (1) joining as the members of 'English Conversation Club', (2) observing sequences of the speech event, (3) observing the style of speech in the conversation, (4) recording the conversation to find hesitation phenomena and (5) documenting the events by taking photo and video.

\section{FINDINGS AND DISCUSSIONS}

\section{Hesitation Phenomena}

"Hesitation phenomena is the various patterns of hesitating in speech" (Rose, 2013). In English community, speech is performed in a form of conversation practices that have been embedded in every single activity of ECC's agenda. As the EFL learners, it is important for them to learn English through exercising of conversation. The difficulty, however, will always be faced by them in conducting conversation activity. According to Chomsky, as cited in Traxler and Gernsbacher (2006), "speech by adults is so full of hesitations, false-starts, mispronunciations, and ungrammaticalities". Thus, the writer as the participant-observation attempts to pay attention more to the member's practices.

Regarding conversational interaction, the activity covers act sequences of events, which are opening (introductory section), main agenda (discussion) and closing. These set of events is arranged by applying open-dialog direct in friendly and neutral sets of tone and the attitude for each learner to motivate the practice of English language. Additionally, the regulation of the activities governs the set of events and the learners' action to be engaged in turn taking the system as well as the hesitation that occurred, with the loudness voice and sociability situations. In this case, the writer examines the types of hesitation phenomenon occurred in the interactions among EFL learners. The detail of findings are presented below: 


\section{Silent pause}

Silent pause or unfilled pause is the interval/duration of silence within speech. During this moment, the speaker will not produce any sentences or even sounds to fill their speech. Based on the writer's observation, she found several examples. Here, FI is the instructor and $\mathrm{LR}$ is the member who is the learner.

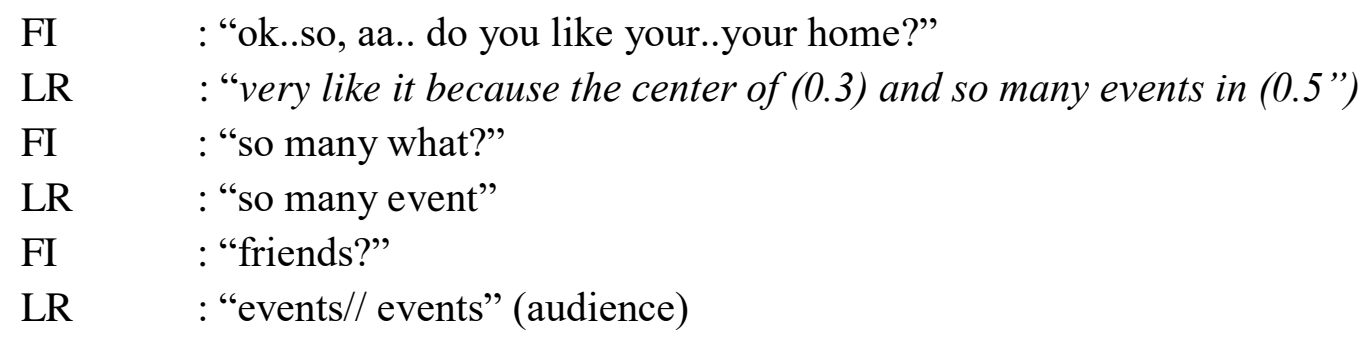

(excerpt 1)

In excerpt 1 , the conversation includes instructor and one of the members. It can be seen that LR, as the learner, is being hesitated in answering FI's question. The instructor actually gives the question spontaneously. Therefore, the learner uses silent pause twice that first is after saying the center of (0.3) and many events in (0.5). In this case, the speaker reminds silence because she/he may think about what answer should be given.

\section{Filled pause}

During the moment of pause, people are not silenced at all. However, its silence is filled with the insertion of a word such as $u h m$ or $u h$.

FI : "Dena, any ideas to talk about?"

LR : "Uhm..uhm..maybe about (0.2) maybe I have what is the idea about how the teenager now. The behavior of teenager that $u h h$..they tend to be more. What is it like (0.3)..uhh.. what is it like an independent."

(excerpt 2)

The context in excerpt 2 is a big group discussion. This situation depicts how the instructor attempts to ask the learner about a topic that will be discussed. When she expresses her opinion, the speakers make a pause for a while. In the beginning, she hesitates before giving a suitable idea since she needs time to decide which idea is better to explain. The way how she makes a decision tends to make pause by uttering the sounds such as $u h m m . .$. and $u h h$.

\section{Lengthenings}

Lengthenings occurs when speakers take a pause by articulating the word to be more longer.

L : "Personally, I think yes." 
FI : : "Which culture?"

L: "Our Javanese culture. The way-culture is not only a dance. The way how we-put on clothes..."

(excerpt 3)

The conversation takes place when the instructor specifically asks about 'which culture?' It emphasizes which culture that should be discussed because Indonesia has many cultures. Then the learner tries to explain this specific culture. It can be seen that learner utters the wayand how way- by producing a long voice. The use of (-) remarks words longer. At this moment, the speaker gets interrupted while thinking the explanation that should be said, so that the words is getting longer.

\section{Repeats/restarts}

Repeat or restart is types of hesitation when the speaker repeats the same word at the time, so he hides the part of being hesitated. Here are the excerpts:

LR : “... there are many cultures that penetrate to our..our country Indonesia. Western culture, Korean or Japanese etc. So, how the best way to protect or reserve our culture that our culture wish - will not disappear, disappear naturally."

FI : "Ok. Good! How to protect our culture, right? How to protect our culture. Ok. Dina!"

(excerpt 4)

Based on the example above, there are two occurrences of being hesitated. Firstly, learner repeats the words twice such as "our..our country" and "disappear, disappear" naturally. Those two repeated words have the same spelling and also pronunciation. Repetition is another form of disfluency, in this case, the speaker hesitates by repeating the words, but without making the correction. However, a reason beyond it should be captured. It is because he emphasizes those specific words. It also indicates that the speaker wants to make a clear explanation related to information of culture in Indonesia.

Secondly, repetition is uttered by the instructor that is "how to protect our culture". He repeats all sentences said based on two reasons. Asking agreement toward other learners is the first reason to discuss a topic. It can be seen by the usage of 'right' indicating a question tag. Then, he is being hesitated by saying the previous utterances spontaneously which he has no idea to speak other words or sentences. 


\section{False starts}

False starts can occur when a speaker utters or speaks the words, then stop in the middle of a sentence. The utterances are completely unfinished.

LR : "So what do you think about the behavior of teenagers nowadays?"

FI : "then I write it down. So, they don't talk. Ten people. They all in a round table and everybody ....

Others : (laughing)

(excerpt 5)

The excerpt 5 presents the situation of conversation between learner and instructor. When the instructor responds to the learners, it seems that he does not finish the utterances. He produces complete utterances in the beginning, but it is not totally complete in the middle. This situation can occur when the speaker is being interrupted by other members, so he stops and not finish his utterances.

\section{Self-correction}

Self-correction can emerge immediately when the speaker is aware if he/she makes mistake on what is being uttered. The writer finds the example of self-correction as follows:

FI : "Dina! Your topic, your topic, is very, is too sophisticated to me naturally. Terlalu canggih buat saya. But this is not my idea. I think I will give to... maybe you (pointing), you like it?"

LR : :yes, like"

FI : "Like, we will talk about it. I am not...I am not the decision marker. How to protect our culture. Do you think you have problem with this? Do you think you have problem with our culture?"

(excerpt 6)

An example displays that the instructor makes self-correction during his speaking twice. Previously, he comments on leaner's opinion that wants to discuss the Korean wave. He makes a hesitation by saying "is very, is too sophisticated" to me reflecting Korean culture. Another utterance is "Do you think you have problem with this? Do you think you have problem with our culture?" Those two utterances indicate the phenomena of self-correction. When the speaker utters the sentences, he is aware of making mistakes and inappropriate use of words. Therefore, he is being hesitated by correcting the words directly at the moment. 


\section{Reasons for Being Hesitant in Conversation}

For psycholinguist, hesitation phenomenon is acceptable from being disruption since they provide information on how the speakers construct the utterances and the choices that they have to make as they talk. (Warren, 2013). Being hesitant among EFL learners is acceptable because English is not their native language. Somehow, doing hesitation is part of the process of producing the language in expressing the opinions and arguments. Due to these considerations, there are the reasons why EFL learners are often being hesitant during a conversation. One of them is unable to express. Conversation practices motivate the learners to have interaction among other learners. Nevertheless, some of them feel that their background knowledge of English is still limit. It is common for learners to produce the sound such as ' $u h m$ ' and ' $u h$ ' indicating they do hesitate in speaking. The production of ' $u h m$ ' and 'uh' as said by Juan (2006), what linguist called as neutral vowel sound that is the easiest sound to produce in speech human sounds. In establishing a smooth interaction among EFL learners, they need to have something to say in mind. The learners who have a weak vocabulary and poor grammar will be difficult to construct a good sentence. As the indication, they will hesitate to utter the words that can be referred to the idea of having poor communication skill (Khattry, 2016). Hence, the reasons mentioned conforming with spoken language which speech is occurring spontaneously and naturally (Pridham, 2001).

\section{CONCLUSION}

In English conversation class, hesitation phenomenon emerges in the interaction among EFL learners in speaking English which involves both instructor and learner. Hesitation phenomena uttered by the learners since English is actually not their native language. The conversation interaction found some hesitation phenomenon such as silent pause, filled pause, lengthenings, repeats/restarts, a false start, and self-correction. It is impossible for them to always speak smoothly without any disruption. Moreover, the reason for being hesitated is unable to express the language and the poor communication skill. Thus, the emergence of hesitation phenomenon in English conversation occurs spontaneously and naturally due to the reason that the processing of language in the brain is not as easy as it is produced directly through the utterances of words and sentences.

\section{REFERENCES}

Carroll, D. W. (2007). Psychology of language, (5 ${ }^{\text {th }}$ ed). USA: Thomson Wadsworth.

Cowles, H. W. (2011). Psycholinguistics 101. New York: Springer Publishing Company. 
Creswell, J. (2007). Qualitative inquiry and research design, (2 ${ }^{\text {nd }}$ ed.). UK: Sage Publications.

Duranti, A. (1997). Linguistic anthropology. Cambridge: Cambridge University Press.

Gold, R. L. 1969. Roles in sociological field observations. In G. J. McCall and J. L. Simmons (Eds.), Issues in participant observation (pp. 30-39). Addison-Wesley

Harley, T. (2001). The psychology of language, ( $2^{\text {nd }}$ ed.). New York: Psychology Press Ltd.

Harley, T. A. (2010). Talking the talk. language, psychology and science. Hove and New York: Psychology Press. Taylor and Francais Groups.

Juan, S. (2006). Why do we say 'um', 'er', or 'ah' when we hesitate in speaking? Retrieved $\begin{array}{llll}\text { February } 13, & 2018 & \text { from }\end{array}$ https://www.theregister.co.uk/2006/05/06/the_odd_body_language_fillers/

Khattry, K. (2016). Why do I hesitate to start talking? Retrieved February 13, 2018 from https://www.quora.com/Why-do-I-hesitate-to-start-talking.

Kosmala, L., \& Morgenstern, A. (2017). A preliminary study of hesitation phenomena in L1 and L2 productions: a multimodal approach. Proceedings of DiSS 2017. Royal Institute of Technology, Stockholm Sweden.

Pridham, F. (2001). The language of conversation. London and New York: Routledge Taylor and Francis Group.

Reitbrecht, S. \& Hirschfeld, U. (2015). The impact of fluency and hesitation phenomena on the perception of non-native speakers by native listeners of German. ICPhS. Retrieved January, 102018 from https://www.semanticscholar.org/paper/The-impact-of-fluency-andhesitation-phenomena-on-Reitbrecht Hirschfeld/ff904ec6c19da5e568df8c9cc5e31e2f0f9c5dbd.

Rose, R. L. (2012). A brief taxonomy of hesitation phenomena. Retrieved January, 102018 from http://filledpause.com/taxonomy.

Rose, R. L. (2013). Crosslinguistic corpus of hesitation phenomena: A corpus for investigating first and second language speech performance. Proceedings of the 14th Annual Conference of the International Speech Communication Association (Interspeech 2013), Lyon, France, 992-996.

Rymes, B. (2009). Classroom discourse analysis: A tool for critical reflection. Cresskill, NJ: Hampton Press.

Spradley, J. P. (1980). Participant observation. New York: Harcourt Brace Jovanovich College.

Traxler, M. J. \& Gernsbacher, M. A. (2006). Handbook of psycholinguistics, (2 ${ }^{\text {nd }}$ ed.). USA: Academic Press.

Thornbury, S. \& Slade, D. (2006). Conversation: From description to pedagogy. Cambridge: Cambridge University Press.

Warren, P. (2013). Introducing psycholinguistics. Cambridge: Cambridge University Press. 